\title{
Frustrative nonreinforcement of operant responding: Magnitude of reinforcement and response force effects'
}

\author{
JOHN G. CARLSON, UNIVERSITY OF MINNESOTA, \\ Minneapolis, Minnesota
}

Intermittent nonreinforcement between two successive reinforcement schedule components was shown to facilitate the performance of rats in the second component. The strength of the effect appeared to be directly related to the magnitude of reinforcement but unaffected by, a threefold increase in the operating force of the response lever.

In some recent investigations of frustrative nonreinforcement, an operant analogue to the Amsel double runway has been used (e.g., Davenport \& Thompson, 1965). In this method, reinforcement is intermittently omitted in the first of two successive reinforcement schedule components. Responding in the second component following nonreinforcement in the first appears to be facilitated with respect to responding following reinforcement. This effect resembles that commonly found in runway frustration experiments (cf. Amsel, 1958).

The present study is the first of a series of experiments aimed at further exploring this "operant frustration effect." Its specific purposes were twofold: first, to replicate the nonreinforcement experiment of Davenport and Thompson using a different species and, second, to investigate the roles of magnitude of reinforcement and response force in the nonreinforcement effect.

Subjects. Eight male Long-Evans hooded rats, 90 days old at the beginning of the experiment, served as Ss. They were maintained at $85 \%$ of free-feeding body weight.

Apparatus. Two Foringer operant conditioning chambers, approximately $14 \mathrm{in}$. in length, width, and height, were each housed in fan-ventilated, sound-resistant enclosures. Located on one wall of the chamber were two automatically retractable response levers requiring $15 \mathrm{~g}$ operating force, one lever on each side of a food trough. The levers were spaced $8.5 \mathrm{in.}$ from center to center. On the same wall were two small jewel lights, one above each lever, and a house light. Reinforcements in the form of $.045 \mathrm{~g}$ Noyes rat pellets were dispensed into the food trough by an automatic feeder. Programming and recording equipment were located in an adjacent room.

Training Procedure. Half of the Ss were assigned to each chamber and given two days of adaptation, $75 \mathrm{~min}$ per day, during which the response levers were retracted and the house light was on. Following this, three sessions of magazine training were administered, 75 reinforcements per session, with variable interreinforcement intervals averaging $60 \mathrm{sec}$. A response lever was then introduced and lever press training was begun. Within the first four sessions, Ss were trained to make five responses on the right lever for each reinforcement (one pellet).

Next, Ss were placed for two days on the following schedule. The left (L) response lever entered the chamber simultaneously with the onset of the left jewel light and the house light. Five responses (fixed ratio, $F_{L_{L}} 5$ ) delivered one pellet, terminated the left jewel light, and retracted the $L$ lever from the chamber. Immediately, the right $(R)$ lever was inserted into the chamber and the right jewel light was turned on. Completion of $F_{R} 5$ turned off the jewel light and the houselight and retracted the $R$ lever. This sequence constituted a trial. An intertrial interval of variable duration (mean $=30 \mathrm{sec}$ ) followed during which all lights were off and both levers retracted. A daily session consisted of 30 trials.

During the next three sessions, the response requirement on each lever was increased to FR 10. Also the interval between $L$ lever retraction and $R$ lever insertion, the midtrial interval, was increased to 5 sec. In the following 10 sessions, the response requirement was increased to $F R_{L} 15 F R_{R} 15$ and the number of trials per session was reduced to 20 . Beginning on Day 7 of this phase, two additional "warmup" trials, on which data were not recorded, were added at the beginning of each daily session.

Testing Procedure. Six test sessions were then administered. All aspects of the test session procedure were the same as in the immediately preceding training phase with the exception that on a random half of the daily trials (nonreinforced trials) reinforcement was omitted for responses on the $L$ lever. The magnitude of reinforcement in each schedule component was one pellet.
Two additional days of training (no nonreinforced trials) were given in which reinforcement in each component was increased to two pellets. Then, eight more test days were administered. All features of this test phase were the same as in the preceding one, with the exception that the magnitude of reinforcement now remained at two pellets.

In an attempt to reduce rate of responding on the $R$ lever to a level which would better reflect the effects of nonreinforcement, six further test sessions were given with the $R$ lever operating force requirement increased to $30 \mathrm{~g}$ from its previous $15 \mathrm{g.}^{3}$ Then the $\mathrm{Ss}$ were split into two groups of four. For one group, the R lever force was increased to $45 \mathrm{~g}$; for the other group, the force was $15 \mathrm{~g}$. On the following day, the first group was run with the $15 \mathrm{~g}$ force and the other group with $45 \mathrm{~g}$. This daily alternation of force requirement was continued for eight days. In all sessions, Ss were nonreinforced for $F_{\mathrm{L}} 15$ on a random half of the trials.

Starting and response times were cumulated across a session for each $\mathbf{S}$. Starting time was the period between the insertion of the $R$ lever and the first lever press on FRR 15 . Response time was the time spent in completing the ratio after the first lever press.

Results and Discussion. Figure 1 shows test performance in the first eight test sessions at the two levels of reinforcement magnitude. Means of logs of cumulative daily starting and response times appear in the left and right halves of the figure, respectively.

It is apparent that nonreinforcement preceding $R$ lever responding facilitated both starting and response times. Also, the nonreinforcement effect was greater at the larger magnitude of reinforcement. At the one-pellet reinforcement magnitude, analyses of variance showed that none of the differences between reinforced and nonreinforced trial starting times or response times was statistically significant at the .05 level. At the two-pellet magnitude, however, the facilitation in performance on nonreinforced trials was significant in both measures (starting time, $F=$ $10.98, \mathrm{df}=1 / 7, \mathrm{p}<.025 ;$ response time, $\mathrm{F}=13.41, \mathrm{df}=1 / 7, \mathrm{p}<$ $.01)$. These differences were also quite consistent for individual Ss.

The results parallel those obtained in runway studies of frustrative nonreinforcement. In addition, these data provide statistical confirmation of the effects of nonreinforcement obtained in similar operant settings, such as in the Davenport and Thompson study in which monkeys were used. The apparent increase in the nonreinforcement effect with the shift to the larger magnitude of reinforcemen: is also consistent with results of Peckham and Amsel (1964).

By increasing the $R$ lever operating force in the last eight sessions, it was hoped that the high level of performance on the FR schedule would be reduced, thereby making the facilitative effects of nonreinforcement even more apparent. The threefold increase in response force did produce an increase in starting times $(\mathrm{F}=7.29, \mathrm{df}=1 / 7, \mathrm{p}<.05)$. However, response times were not significantly affected $(F<1.0)$. Moreover, though the nonreinforceinent effect again appeared in this phase (starting time, $F=$

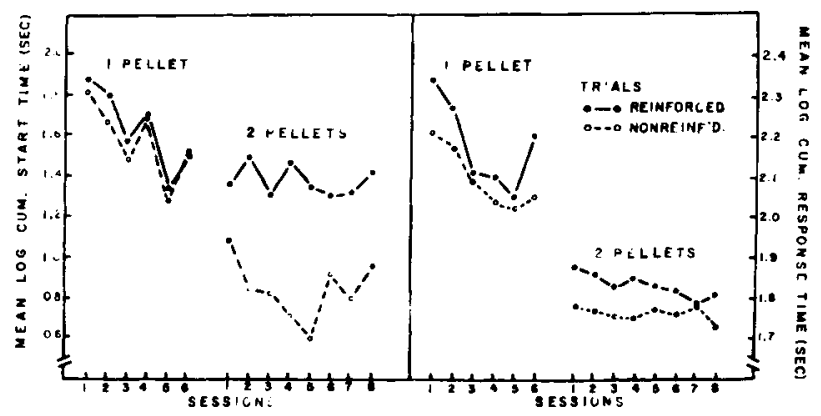

Fig. 1. Means of logs of cumulative starting and response times on 10 reinforced and 10 nonreinforced trials at two levels of reinforcement magnitude. 
$7.11, \mathrm{df}=1 / 7, \mathrm{p}<.05 ;$ response time, $\mathrm{F}=12.12, \mathrm{df}=1 / 7, \mathrm{p}<$ .025 ), the magnitude of the effect in both measures appeared to be unrelated to the force requirement. This was borne out by the nonsignificance of the relevant interaction terms in the analyses of variance $(p>.05)$. Thus, in spite of the high level of performance generated by the FR schedule, the magnitude of the nonreinforcement effect was apparently not constrained by possible ceiling effects, at least in the starting time measure.

\section{REFERENCES}

AMSEL, A. The role of frustrative nonreward in noncontinuous reward situations. Psychol Bull., 1958, 55, 102-119.

CARLSON, J. G. Effects of consummatory and instrumental response blocking. Unpublished doctoral dissertation, University of Minnesota, 1967.
DAVENPORT, J. W., \& THOMPSON, C. I. The Amsel frustration effect in monkeys. Psychon. Sci., 1965, 3, 481-182.

PECKHAM, R. H., \& AMSEL, A. Magnitude of reward and the frustration effect in a within-subjects design. Psychon. Sci, 1964, 1, 285-286.

\section{NOTES}

1. This study is based on a dissertation (Carlson, 1967) and was supported in part by grants to the Center for Research in Human Learning, University of Minnesota. Grateful acknowledgment is due Dr. M. A. Trapold, who provided assistance with the research and this manuscript.

2. Now at Department of Psychology, University of Hawaii, Honolulu, Hawaii 96822.

3. Details of these phases may be found in Carlson (1967). 